\title{
POTRET DINAMIS ISLAM INDONESIA
}

\author{
Ngainun Naim \\ Dosen Institut Agama Islam Negeri Tulungagung, Indonesia \\ naimmas22@gmail.com
}
Judul : Islam Indonesia Dialektika Agama, Budaya, dan Gender
Penulis : Ade Yamin, Damanhuri, Mufliha Wijayati, Nikmatullah, Norman Ohira, Zukfatun Ni'mah
Penerbit : LKiS Yogyakarta
Cetakan $\quad: 1,2020$
Tebal : xx+296 halaman, ukuran $15 \times 23$

DOI: https://doi.org/10.32488/harmoni.v20i1.452

\begin{abstract}
Abstrak
Islam sebagai agama bersifat tunggal tetapi pemahaman terhadap Islam teraktualisasi dalam corak keberagamaan yang bermacam-macam. Masing-masing corak tumbuh dan berkembang seiring dengan dinamika perkembangan masingmasing masyarakat. Riset tentang relasi Islam dan budaya lokal sebagaimana ditampilkan oleh enam orang penulis buku ini menunjukkan bahwa potret Islam Indonesia itu sangat dinamis. Buku ini merupakan sinopsis disertasi enam orang penulisnya. Sebagai disertasi dari berbagai perguruan tinggi dan bidang ilmu, buku ini menampilkan potret Islam Indonesia yang unik dan khas. Telaahnya cukup mendalam dan bisa dipertanggungjawabkan secara akademis. Terbitnya buku ini memberikan kontribusi penting dalam memahami potret Islam Indonesia yang sangat dinamis.
\end{abstract}

Kata Kunci: Budaya Lokal, Corak Keberagamaan, Islam Indonesia,

Islam Indonesia memiliki karakteristik khas yang unik. Keunikan ini merupakan aktualisasi dari dialektika antara Islam dengan budaya lokal. Dialektika ini secara umum mengambil formula akulturasi, baik menyerap atau dialog. Substansinya adalah saling memperkaya pada wilayah budaya dan aspek kehidupan social (Muqoyyidin, 2013).
Kekayaan khazanah Islam Indonesia sesungguhnya merupakan mozaik yang sangat menarik. Wajar jika riset demi riset terus dilakukan. Meskipun demikian selalu tersedia ruang kosong yang bisa dimasuki. Riset sesungguhnya memerlukan kecermatan peneliti dalam membaca realitas. Realitas yang sama akan dilihat oleh setiap peneliti secara berbeda-beda, tergantung pada paradigma yang dianut (Hasbiansyah, 2004).

Buku ini mewakili kecermatan para penulisnya dalam menemukan isu, mendalami, mengolah, dan kemudian menjadikan sebagai topik penelitian. Ada enam penulis di buku ini. Mereka adalah para calon doktor yang lolos seleksi program PIES (Partnership in Islamic Education Scheme) hasil kerja sama Kementerian Agama dengan The Australian National University (ANU) Canberra. Selama setahun mereka mendapatkan penguatan teori, metodologi, dan pematangan substansi disertasi. Proses yang semacam ini menjadikan disertasi yang mereka tulis menjad jauh lebih berbobot.

Penulis pertama adalah Ade Yamin, Dosen IAIN Fatahul Muluk Jayapura. Ia menulis dengan judul "Islam Sumber 
Kebanggaan: Dialektika Agama, Budaya dan Politik Komunitas Dani di Papua". Tulisan Ade Yamin berkisah tentang kehidupan komunitas Dani Muslim di Lembah Balim Wamena. Mereka merupakan suku asli Papua namun dalam kehidupan sehari-hari mereka terdiskriminasi justru di kampung halamannya sendiri. Faktor penyebab diskriminasi adalah agama yang mereka anut, yaitu Islam. Diskriminasi-selain disebabkan oleh faktor agama-bisa juga disebabkan oleh prasangka sosial dan intensi (Adelina et al., 2017). Memang saat mereka memeluk Islam maka mereka harus menghadapi tantangan fisik dan non-fisik, langsung dan tidak langsung.

Penelitian Ade Yamin mengungkapkan fenomena yang sangat unik, yakni bagaimana Dani Muslim menjadi seorang Muslim. Jangan dibayangkan mereka sama seperti kaum Muslim lainnya. Mereka memang telah memeluk agama Islam tetapi dalam kehidupan sehari-hari mereka masih menjalankan aturan adat yang bertentangan dengan ajaran Islam. Salah satu praktik yang menonjol dan bertentangan dengan ajaran Islam tetapi tetap dilakukan Muslim Dani adalah yang berkaitan dengan "babi". Hal ini disebabkan karena babi menempati posisi penting sebagai pusat dari semua ritual penting Dani, seperti mahar bagi perkawinan, makanan untuk upacara, dan sebagainya. Realitas semacam ini membuat Ade Yamin menyimpulkan bahwa Islam datang ke komunitas Dani Muslim sebagai kebetulan. Sebagai kebetulan-bukan murni kesadaranmembawa konsekuensi berbeda dalam pengetahuan, kesadaran, dan aktualisasi ajaran Islam. Cara berislam memang tidak hanya mengikuti pola linier yang telah mapan, tetapi juga menggunakan pola berbeda (Bruinessen, 1999), sebagaimana yang dilakukan suku Dani.
Perjuangan mengenalkan Islam sungguh tidak ringan. Bagi suku Dani, Islam bukan hanya agama tetapi juga merupakan hasil perjuangan berdarahdarah dan pertaruhan harga diri (h. 43). Meskipun demikian pelan tetapi pasti semakin banyak orang Dani yang memeluk Islam dan mengamalkan ajaran Islam dalam kehidupan sehari-hari. Yamin menjelaskan secara menarik tentang bagaimana ada perbedaan persepsi antar generasi terkait keberislaman mereka. Generasi tua tetap dengan identitas mereka yang secara formal telah memeluk Islam namun perilaku sehari-harinya belum sejalan dengan ajaran Islam. Harapan diberikan kepada generasi muda agar mereka nantinya menjadi lebih baik dalam menjalankan ajaran Islam (h. 27).

Pertemuan antara Islam dan tradisi pada masyarakat Dani ditandai oleh tipisnya batas antara halal dan haram. Namun seiring waktu terjadi transformasi dalam masyarakat Dani Muslim. Proses interaksi dan komunikasi generasi muda Dani Muslim menghasilkan pengetahuan, pemahaman, dan kesadaran yang lebih baik dalam menjalankan ajaran Islam. Transformasi semacam ini ditandai dengan semakin meningkatnya tingkat ketaatan pada ajaran Islam (Prasetyo, 2020).

Tulisan kedua karya Damanhuri, Dosen INSTIKA Guluk-Guluk Sumenep, Madura. Ia menulis judul "Kitab-Kiai Madura: Kuasa Teks dan Otoritas Keagamaan". Tulisan Damanhuri mengulas perspektif menarik terkait dengan tumbuh dan berkembangnya budaya literasi di kalangan kiai Madura. Pesantren sekarang ini memang mengalami dinamika menarik terkait literasi, termasuk literasi digital juga telah dimasuki oleh kalangan pesantren (Ja'far, 2019; Setyaningsih et al., 2020) dan literasi keuangan (-, 2017)untuk membuat keputusan ekonomi yang tepat dalam berkonsumsi dan terhindar dari 
gaya hidup tinggi tentunya dibutuhkan pengetahuan tentang literasi keuangan (financial literacy). Riset-riset tersebut memperkuat tradisi literasi yang sesungguhnya sudah cukup lama eksis di dunia pesantren (Hasanah, 2015).

Tulisan Damanhuri menghadirkan perspektif yang lebih kaya. Menurut Damanhuri, banyak karya kiai Madura tidak bisa dilepaskan dari perkembangan pendidikan yang ditempuh para kiai penulis kitab. Penelitian Damanhuri menyebutkan bahwa sampai dengan tahun 2017, sebagaimana identifikasi yang dilakukannya, ada 194 buah kitab karya para kiai Sumenep Madura. Tentu ini merupakan jumlah yang cukup signifikan. Jumlah tersebut menunjukkan bahwa literasi semakin tumbuh dan berkembang.

Hasil analisis Damanhuri menemukan bahwa dari 194 kitab yang ada, bentuknya bermacam-macam. Ada kitab yang memang ditulis dalam bahasa Arab, ada yang berbentuk terjemah, syarah, mukhtasar, dan nukilan (h. 67). Keanekaragaman bentuk kitab tersebut juga berkaitan dengan berbagai faktor yang berkait-kelindan. Tentang alasan menulis kitab juga bermacam-macam, mulai alasan ibadah, sebagai bentuk respon terhadap pertanyaan masyarakat, dan juga karena memenuhi kurikulum pendidikan lembaga pendidikan tempat kiai mengajar (h. 68-70). Aspek yang lebih penting adalah para kiai kini semakin kreatif dan produktif dalam menulis.

Aspek yangjuga menarik diulas oleh Damanhuri adalah relasi antara teks dan konstruksi otoritas keagamaan. Menurut Damanhuri, relasi tersebut membentuk beberapa jaringan, yaitu jaringan kitab, intelektual, pesantren, dan kekerabatan. Aspek lain yang juga menarik adalah Subbab "Relas Kuasa Pengetahuan dalam Kitab Kiai". Bagian ini, dengan pisau analisis dari teori Michael Foucauld, membedah relasi kuasa dalam teks kitab yang ditulis. Analisis Damanhuri cukup tajam dan membongkar berbagai kepentingan yang ada di balik setiap kitab yang ditulis oleh para kiai.

Bagian ketiga memuat tulisan Mufliha Wjayati, Dosen IAIN Metro Lampung. Ia menulis dengan judul, "Punishing Women: Diskriminasi terhadap Perempuan yang Mengajukan Cerai di Peradilan Agama Indonesia". Tulisan Mufliha membedah fenomena perceraian di mana perempuan yang menggugat dan memperkaya riset-riset dengan tema sejenis yang sudah pernah dilakukan sebelumnya (Arifin, 2017; Ulfah, 2011; Zuhrah, 2019). Mufliha secara kritis melihat betapa perempuan "terhukum" oleh peraturan perundangundangan dan sekaligus terhukum dalam proses persidangan di dalam putusan pengadilan. Studinya dilakukan di Pengadilan Agama Metro dan Kalianda, Lampung. Argumentasi terhukumnya perempuan berdasarkan inventarisasi hukum peraturan perkawinan dan perceraian, pembacaan terhadap dokumen putusan, observasi persidangan, wawancara dengan beberapa hakim, panitera, pengacara, dan perempuan yang berperkara (h. 100). Menurut Mufliha, fenomena tingginya perempuan yang mengajukan gugatan cerai merupakan bentuk 'perlawanan' meskipun berujung kekalahan karena tidak mendapatkan hak-hak pasca perceraian (h. 101).

Ada tiga hal yang dianalisis Mufliha sebagai pintu masuk marginalisasi perempuan meskipun regulasinya tampak netral. Pertama, persamaan hak untuk mengajukan perceraian. Kedua, kriteria nusyuz yang diskriminatif. Dan ketiga, prosedur verstek yang secara umum merugikan perempuan. Ketiga hal di atas menjadi pintu untuk analisis dan membongkar berbagai perilaku diskriminatif terhadap perempuan. Ditinjau dari sisi yuridis, hukum keluarga di Indonesia sesungguhnya 
sangat progresif. Mufliha mengutip pendapat banyak ahli tentang hal ini. Meskipun demikian bukan berarti hukum keluarga merupakan hukum yang tanpa kelemahan. Menggunakan feminist legal theory dan gender analysis theory model Mansoer Fakih membuat Mufliha menemukan sisi kelam dan ketidakadilan di tengah progresivitas hukum keluarga.

Aspek yang menarik lain adalah justice broker, yaitu pendamping para pihak yang berperkara di pengadilan tetapibukan berprofesi sebagai pengacara. Masyarakat menyebut mereka sebagai "calo perkara" atau "calo pengadilan". Mereka ini berperan penting dalam kontekspengurusanperkaradipengadilan agama karena literasi hukum masyarakat kita yang memang masih rendah. Namun kelemahannya, justice broker ini cenderung menyarankan agar perempuan yang menggugat agar prosesnya sederhana, cepat, dan biayanya murah (h. 107). Dari perspektif gender, kondisi semacam ini berimplikasi pada mensubordinasi perempuan sebagai pihak yang tidak memiliki pilihan dan posisi tawar untuk menghindar dari pilihan sebagai penggugat. Selain tersubdordinasi juga mengalami kekerasan ekonomi karena biayanya yang mahal. Padahal menurut Mufliha, perceraian semestinya dilihat secara komprehensif. Pihak suami dan istri seharusnya digali informasinya secara berimbang. Hal ini penting artinya dalam kerangka menciptakan keadilan. Memang ada hakim yang memperlakukan perempuan secara diskriminatif, meskipun ada juga hakim yang ramah dan lemah lembut.

Bagian keempat ditulis oleh Nikmatullah, dosen UIN Mataram, dengan judul, "Hak-hak Perempuan dalam Perkawinan: Interpretasi Tuan Guru tentang Hadis Pernikahan". Tuan Guru menjadi objek riset yang cukup produktif. Tinjauannya bermacammacam, mulai dari aspek perubahan sosial (Fahrurrozi, 2018), otoritas keagamaan mereka (Kingsley, 2014), sebagai tokoh pendidikan (Aswasulasikin et al., 2015), peran politik (Anwar, 2018), dan peran profetik (Umam, 2017). Sejauh penelusuran belum ada riset yang pernah dilakukan sebagaimana ditulis oleh Nikmatullah. Ada kesamaan antara Mufliha Wijayati dan Nikmatullah, yakni sama-sama mengkritisi ketidakadilan terhadap perempuan. Namun demikian tentu saja ada banyak perbedaannya, salah satunya adalah perbedaan alat analisis. Jika Mufliha menggunakan feminist legal theory dan gender analysis Mansour Fakih, Nikmatullah menggunakan Islamic feminist approach. Ia menganalisis 50 buah hadis. Argumen utama Nikmatullah adalah mayoritas Tuan Guru mempunyai pemahaman konservatif tentang hadis pernikahan yang mempunyai dampak terhadap budaya patriarki dalam masyarakat Sasak.

Secara menarik Nikmatullah mendedah bagaimana argumennya dibangun dan dibuktikan lewat penelitian. Menurut Nikmatullah, ada dua metode memahami hadis oleh Tuan Guru, yaitu secara tekstual dan kontekstual. Metode tekstual dalam memahami hadis bersifat legalistik-literalis yang berimplikasi pada single interpretasi. Sedangkan metode kontekstual berimplikasi pada multiinterpretasi. Analisis yang dilakukan Nikmatullah menemukan bahwa pemahaman Tuan Guru mengenai hadis pernikahan berimplikasi pada terjadinya diskriminasi terhadap perempuan. Bentuk diskriminasinya adalah subordinasi; stereotype, beban ganda, dan kekerasan. Nikmatullah menguraikan panjang lebar tentang bagaimana diskriminasi terjadi pada perempuan, penyebabnya, dan manifestasinya.

Di tengah ketidakmampuan perempuan dalam menghadapi dominasi laki-laki, Nikmatullah menemukan fenomena menarik di Lombok, yaitu 
tentang agensi perempuan. Perempuan sesungguhnya memiliki kemampuan melakukan sesuatu atas pilihan sendiri (h. 168-173). Inilah yang oleh Nikmatullah disebut sebagai agensi. Bentuknya ada tiga, yaitu personal, institusional, dan sosial.

Bagian kelima ditulis oleh Norman Ohira, dosen IAIN Kerinci, dengan judul, "Ungkapan Ke-Melayuan dalam Teks Melayu 1500-1800 di Selat Malaka". Melayu memang selalu menarik untuk diteliti. Selalu terbuka ruang-ruang untuk dijelajahi secara lebih mendalam. Norman Ohira mengambil sisi yang jarang diminat, yaitu teks Melayu pada tahun 1500-1800. Riset semacam ini tentu membutuhkan ketekunan, kecermatan, dan kesabaran. Argumen yang dibangun di tulisan Norman adalah wacana yang berlaku tentang Melayu didasarkan pada pandangan eksternal dan berorientasi politik, sedangkan teks-teks asli memberikan pemahaman budaya dan sosial yang lebih luas tentang keragaman kehidupan Melayu "tradisional".

Tulisan Norman di buku ini membutuhkan kecermatan dalam membacanya karena berkaitan dengan kajian teks yang cukup rumit, selain juga karena gaya Bahasa Norman yang khas. Sebagai seorang yang tidak memiliki modal dalam kajian ini saya harus membaca secara cermat bagian demi bagian karena minimnya pengetahuan yang saya miliki. Aspek yang saya kira menarik adalah kesimpulan Norman bahwa kemelayuan adalah suatu konsep ungkapan atau ekspresi kultural dari masyarakat yang dinamakan Melayu (h. 202). Norman menjelaskan bahwa aspek ekspresi kemelayuan tidak hanya berkaitan dengan politik kerajaan tetapi juga berkaitan dengan public sphere, government, ekonomi, literature, dan bahasa. Paparan secara detail dari naskah yang diungkapkan Norman memberikan informasi betapa Melayu itu memiliki khazanah yang sangat kaya. Wajar jika banyak sarjana Malaysia yang juga menjadikan melayu sebagai objek riset (Asyikin \& Normalina, 2019).

Temuan lain yang menarik adalah tradisi kepemimpinan perempuan. Norman menemukan bahwa jika raja tidak memiliki anak laki-laki, anak perempuan bisa menjadi penerusnya dengan gelar Sultanah (h. 212). Temuan ini menegaskan bahwa jauh sebelum muncul gerakan gender kontemporer, di Melayu pada masa lalu kesetaraan gender telah menjadi bagian dari kehidupan masyarakat.

Tulisan keenam karya Zulfatun Ni'mah, dosen IAIN Tulungagung. Ia menulis dengan judul, "Perceraian Sepihak: Diskriminasi terhadap Perempuan yang Diwajarkan". Spirit tulisan Zulfatun sejalan dengan yang diusung Mufliha Wijayati dan Nikmatullah. Fokus tulisannya adalah perceraian yang dikaitkan dengan isu hak asasi perempuan yang mana negara memiliki tanggung jawab untuk melakukan intervensi. Zulfatun melakukanrisetdiLombok.Iamenjelaskan bahwa pada masyarakat Sasak, umum seorang suami menjatuhkan talak tanpa proses peradilan. Ini merupakan "tradisi diskriminatif", meskipun masyarakat menganggapnya sebagai hal yang wajar. Padahal praktik perceraian sepihak membuat perempuan kehilangan hak dalam turut menentukan arah perkawinan. Riset Zulfatun menemukan bahwa salah satu penyebabnya adalah pemahaman tekstual Madzhab Syafii yang menyebutkan bahwa talak adalah hak mutlak laki-laki. Bermzdzhab secara qauly berkontribusi mengukuhkan diskriminasi ini. Pembacaan secara tekstual mengabaikan konteks sosial budaya ketika kitab-kitab rujukan disusun oleh para penulisnya (Yusuf, 2014). 
Kondisi ini sulit dirubah karena sebagian besar pihak justru-sengaja atau tidak-ikut melanggengkannya. Legislatif di NTB, misalnya, melihat fenomena perceraian sepihak sebagai fenomena biasa dan wajar. Belum ada inisiatif membawanya menjadi pembahasan dan menjadikannya sebagai isu strategis. Hal yang sama juga terjadi pada eksekutif. Analisis gender belum menjadi bagian dalam penyusunan dan evaluasi program pembangunan. Demikian juga dengan PKK. Zulfatun menemukan bahwa kondisi yang ada memang melanggengkan diskriminasi terhadap perempuan.

Tulisan demi tulisan di buku ini menghadirkan potret yang unik tentang Islam Indonesia. Potret ini menunjukkan bagaimana studi Islam kontemporer sangat kaya warna. Pendekatan yang digunakan juga sangat bervariasi. Bacalah buku ini dan temukan kekayaan pengetahuan, wawasan, dan khazanah Islam Indonesia di dalamnya.

\section{DAFTAR ACUAN}

-, A. S.-. (2017). Model Literasi Keuangan Pondok Pesantren Madura. Prosiding Seminar Pendidikan Ekonomi Dan Bisnis.

Adelina, F., Hanurawan, F., \& Suhanti, I. Y. (2017). Hubungan Antara Prasangka Sosial dan Intensi Melakukan Diskriminasi Mahasiswa Etnis Jawa terhadap Mahasiswa Yang Berasal Dari Nusa Tenggara Timur. Sains Psikologi.

Anwar, M. S. (2018). Dinamika Peran Politik Tuan Guru di Lombok Era Reformasi. Thaqafiyyat: Jurnal Bahasa, Peradaban Dan Informasi Islam.

Arifin, J. (2017). Tingginya Angka Cerai Gugat di Pengadilan Agama Pekanbaru dan Relevansinya dengan Konsep Kesetaraan. Marwah: Jurnal Perempuan, Agama Dan Jender. https://doi.org/10.24014/marwah.v16i2.4137

Aswasulasikin, A., Dwiningrum, S. I. A., \& Sumarno, S. (2015). Tuan Guru Sebagai Tokoh Pembangunan Pendidikan di Pedesaan. Jurnal Pembangunan Pendidikan: Fondasi Dan Aplikasi. https://doi.org/10.21831/jppfa.v3i1.6669

Asyikin, N., \& Normalina, N. (2019). Naskah Persuratan Melayu: Pemeliharaan dan Digitalisasi di Malaysia. Manuskripta. https://doi.org/10.33656/manuskripta. v9i2.150

Bruinessen, M. Van. (1999). Global and local in Indonesian Islam. Southeast Asian Studies.

Fahrurrozi. (2018). Tuan Guru and Social Change in Lombok, Indonesia. Indonesia and the Malay World. https://doi.org/10.1080/13639811.2018.1452487

Hasanah, U. (2015). Pesantren Dan Transmisi Keilmuan Islam Melayu-Nusantara: Literasi, Teks, Kitab Dan Sanad Keilmuan. 'Anil Islam: Jurnal Kebudayaan Dan Ilmu Keislaman. 
Hasbiansyah, O. (2004). Konstelasi Paradigma Objektif dan Subjektif dalam Penelitian Komunikasi dan Sosial. Mediator: Jurnal Komunikasi.

Ja'far, A. (2019). Literasi Digital Pesantren: Perubahan dan Kontestasi. Islamic Review: Jurnal Riset Dan Kajian Keislaman. https://doi.org/10.35878/islamicreview.v8i1.156

Kingsley, J. J. (2014). Redrawing lines of religious authority in Lombok, Indonesia. Asian Journal of Social Science. https://doi.org/10.1163/15685314-04205010

Muqoyyidin, A. W. (2013). Dialektika Islam dan Budaya Lokal Jawa Andik. Ibda, Jurnal Kebudayaan Islam.

Prasetyo, Y. (2020). Transformasi Nilai-Nilai Islam dalam Hukum Positif. Al-Ahkam Jurnal Ilmu Syari'ah Dan Hukum. https://doi.org/10.22515/al-ahkam.v5i1.1943

Setyaningsih, R., Abdullah, A., Prihantoro, E., \& Hustinawaty, H. (2020). Penanaman etika komunikasi digital di pesantren melalui pemanfaatan e-learning. Jurnal Kajian Komunikasi. https://doi.org/10.24198/jkk.v8i1.24538

Ulfah, I. (2011). Menggugat Perkawinan: Transformasi Kesadaran Gender Perempuan dan Implikasinya terhadap Tingginya Gugat Cerai di Ponorogo. Kodifikasia. https://doi.org/10.21154/kodifikasia.v5i1.219

Umam, F. (2017). Tera Ulang Peran Profetik Tuan Guru dalam Konteks Kebebasan Beragama di Pulau Lombok. Ulumuna. https://doi.org/10.20414/ujis.v13i2.367

Yusuf, M. (2014). Memahami Weltanschauung Al-Quran. Sulesana: Jurnal Wawasan Keislaman.

Zuhrah, F. (2019). Perempuan Menggugat: Telaah Perceraian Wanita Muslimah Berkarir di Kota Medan. Miqot: Jurnal Ilmu-Ilmu Keislaman. https://doi.org/10.30821/miqot. $\mathrm{v} 42 \mathrm{i} 2.520$ 